\title{
Comparison of community-acquired pneumonia requiring admission to hospital in HIV- and non-HIV-infected patients
}

\author{
CLAIRE TOUCHIE MD FRCPC, THOMAS J MARRIE MD FRCPC
}

C TOUCHIE, TJ MARRIE. Comparison of community-acquired pneumonia requiring admission to hospital in HIVand non-HIV-infected patients. Can J Infect Dis 1996;7(4):253-258.

\begin{abstract}
OBJECTIVE: To compare community-acquired pneumonia (CAP) in hospitalized human immunodeficiency virus (HIV) -infected patients with that in hospitalized non-HIV-infected patients by assessing presenting characteristics, etiology and outcomes.

DESIGN: Retrospective chart review.

SETTING: A tertiary care centre in Halifax, Nova Scotia.

POPULATION STUDIED: Thirty-two HIV-infected patients requiring hospitalization for treatment of CAP were identified from September 1991 to October 1993 and compared with 33 age-matched non-HIV-infected patients who presented with pneumonia during the same period.

MAIN RESULTS: The two populations were comparable in age, sex and race. Fifty per cent of the HIV-infected and $20.8 \%$ of the non-HIV-infected patients had had a previous episode of pneumonia. Pneumocystis carinii pneumonia (PCP) accounted for 16 of the 32 episodes of CAP in the HIV-infected patients, while none of the non-HIV-infected patients had PCP. Pneumonia secondary to Streptococcus pneumoniae was more common in the non-HIV-infected patients (five versus one, $\mathrm{P}=0.02$ ). Vital signs and initial $\mathrm{PO}_{2}$ did not differ between the two groups. White blood cell count was lower at admission for the HIV population $\left(5.7 \times 10^{9} / \mathrm{L}\right.$ versus $\left.12.7 \times 10^{9} / \mathrm{L}, \mathrm{P}=0.003\right)$. The HIV patients were more likely to undergo bronchoscopy $(27.7 \%$ versus $0 \%, \mathrm{P}<0.001)$. The length of stay in hospital, transfer to the intensive care unit and necessity for intubation were the same for both groups. The in-hospital mortality for HIV-infected patients was eight of 32 $(25 \%)$ while for the non-HIV-infected patients it was none of $33(\mathrm{P}=0.002)$.

CONCLUSIONS: Patients with HIV infection who present with CAP are more likely to have PCP, to have had a past episode of pneumonia and to die while in hospital than age- and sex-matched non-HIV-infected patients with CAP. (Pour le résumé, voir page 254)
\end{abstract}

Key Words: Community-acquired pneumonia, Human immunodeficiency virus infection, Hospitalization

Department of Medicine, Victoria General Hospital, Dalhousie University, Halifax, Nova Scotia

Correspondence and reprints: Dr TJ Marrie, Victoria General Hospital, 1278 Tower Road, ACC 5014, Halifax, Nova Scotia B3H 2Y9. Telephone 902-428-5553, fax 902-428-7094, e-mail t.j.marrie@dal.ca

Received for publication August 28, 1995. Accepted February 28, 1996 


\title{
Comparaison des hospitalisations pour pneumonie non hospitalière chez des patients infectés ou non au VIH
}

\begin{abstract}
OBJECTIF : Comparer la pneumonie non hospitalière chez des sujets infectés au VIH hospitalisés et la même pathologie chez des patients non infectés au VIH hospitalisés, en évaluant les caractéristiques cliniques, l'étiologie et l'évolution de la maladie.

MODÈLE : Examen rétrospectif des dossiers.

CONCEPT : Établissement de soins tertiaires à Halifax, en Nouvelle-Écosse.

POPULATION ÉTUDIÉE : Trente-deux patients infectés au VIH hospitalisés pour le traitement d'une pneumonie non hospitalière identifiée entre septembre 1991 et octobre 1993, comparés à 33 patients assortis selon l'âge, non infectés par le VIH et ayant présenté la même pathologie pendant la même période.

PRINCIPAUX RÉSULTATS : Les deux populations étaient comparables sur le plan de l'âge, du sexe et de la race. Cinquante pour cent des patients infectés au VIH et 20,8\% des patients non infectés au VIH avaient déjà souffert de pneumonie. La pneumonie à Pneumocystis carinii (PPC) représentait 16 des 32 épisodes chez les sujets infectés au VIH, mais était absente chez les patients non infectés au VIH. La pneumonie à Streptococcus pneumoniae était plus fréquente chez les patients non infectés au VIH (cinq contre un, $\mathrm{P}=0,02$ ). Les signes vitaux et la $\mathrm{PO}_{2}$ initiale étaient semblables chez les deux groupes. La numération leucocytaire était plus basse à l'admission pour la population $\mathrm{VIH}\left(5,7 \times 10^{9} / \mathrm{L}\right.$ contre $12,7 \times$ $\left.10^{9} / \mathrm{L}, \mathrm{P}=0,003\right)$. Les patients VIH étaient plus susceptibles de subir une bronchoscopie $(27,7 \%$ contre $0 \%, \mathrm{P}<0,001)$. La durée du séjour hospitalier, le transfert à l'unité des soins intensifs et le recours à l'intubation ont été les mêmes pour les deux groupes. La mortalité à l'hôpital pour les patients infectés au VIH a été de huit sur 32 (25 \%), alors qu'aucun patient non infecté au VIH sur les 33 inscrits n'est décédé (P = 0,002).

CONCLUSIONS : Les patients infectés par le VIH qui se présentent avec une pneumonie non hospitalière sont plus susceptibles de souffrir de PPC, d'avoir déjà souffert de pneumonie et de décéder durant le séjour hospitalier que les patients non infectés au VIH atteints de pneumonie assortis selon l'âge et le sexe.
\end{abstract}

$\mathrm{P}_{\mathrm{i}}$ neumonia is a common presenting condition in human immunodeficiency virus (HIV) -infected patients. Pulmonary infections account for a great proportion of AIDSdefining illnesses. In previous reports, Pneumocystis carinii pneumonia (PCP) has been the most prevalent respiratory illness in the HIV population with an estimated lifetime risk of $60 \%$ to $85 \%$ if no prophylactic medications are provided $(1,2)$. Magnenat et al (3) studied respiratory diseases in HIVinfected patients and found that $45.5 \%$ had a diagnosis of bacterial pneumonia while $27.7 \%$ had PCP. Bacterial pneumonia has gained such recognition in this population of patients that both the Centers for Disease Control and Prevention (CDC) in the United States and the Laboratory Centre for Disease Control in Canada have added recurrent bacterial pneumonia as an AIDS-defining illness $(4,5)$.

It was our subjective impression that PCP was decreasing as an admitting diagnosis in HIV-infected patients at our hospital. We were also interested in comparing community-acquired pneumonia (CAP) in HIV-infected patients with pneumonia in non-HIV-infected patients to determine the differences, if any, in presentation, etiology, resource utilization and in-hospital mortality.

\section{PATIENTS AND METHODS}

Charts of all HIV-infected patients with a diagnosis of CAP requiring admission to the authors' hospital from September 1991 to October 1993 were retrospectively reviewed. Age(within 10 years) and sex-matched non-HIV-infected patients admitted over the same period with CAP served as the comparison group. The non-HIV-infected patients were identified as part of a prospective observational study of CAP. Pneumonia was defined when at least two of fever, cough, crackles and a new opacity on chest radiograph interpreted by a radiologist as pneumonia were present.
The diagnostic work-up of the pneumonia in both groups of patients was at the discretion of the attending physician. Blood for culture was inoculated into appropriate media (Bactec Plus, Becton Dickinson Diagnostic Instrument Systems, Maryland) and processed with the Bactec 660 Automated System (September 1991 to June 1993) and the Bactec 9240 Automated System (June 1993 to October 1993). Positive cultures were handled according to the laboratory's protocol. Sputum specimens were accepted for culture only if they met the appropriate quality scoring (25 or more polymorphonuclear cells and less than 10 squamous epithelial cells/low power field) as described previously (6). Chest radiographs were reviewed by the authors and data entered onto a form designed for the study.

The etiology of the pneumonia was based on culture and serology reports and was classified as definite or presumptive as defined by Fang et al (7). A definite diagnosis of PCP was made by a positive monoclonal antibody direct immunofluorescence test (Genetic Systems Corporation, Washington) on induced sputum or bronchoalveolar lavage. A presumptive diagnosis of this infection was made in a patient who improved on anti-PCP therapy and when no other etiological agent was identified.

Patients were followed up by reviewing data in the out-patient charts kept on all HIV-infected patients. These patients are seen on a regular basis in the clinic, and a special data collection sheet detailing historical and physical examination data is completed at each visit. Non-HIV-infected patients were followed through the prospective observational study (first six months) and with telephone contacts with family physicians thereafter.

Statistical analysis was done using Fisher's exact test, a corrected $\chi^{2}$ for categorical data and Student's test for continuous variables (8). 
TABLE 1

Abnormalities on admission chest radiographs of HIV- and non-HIV-infected patients with community-acquired pneumonia

\begin{tabular}{|c|c|c|c|}
\hline & HIV-infected & Non-HIV-infected & $\mathbf{P}$ \\
\hline Number of chest radiographs reviewed & 32 & 33 & \\
\hline Interstitial pattern & $19(60 \%)$ & $7(21 \%)$ & $\leq 0.01$ \\
\hline Alveolar pattern & $11(34 \%)$ & $26(79 \%)$ & $\leq 0.01$ \\
\hline Mixed interstitial/alveolar & $2(6 \%)$ & 0 & NS \\
\hline
\end{tabular}

HIV Human immunodeficiency virus, NS Not significant

TABLE 2

Etiological diagnoses of community-acquired pneumonia in HIV-infected patients and in non-HIV-infected patients

\begin{tabular}{lccc}
\hline Etiology & HIV-infected & Non-HIV-infected & P \\
\hline Unknown & $11(34 \%)$ & $24(73 \%)$ & $\leq 0.005$ \\
Pneumocystis carinii & $16(50 \%)$ & 0 & $\leq 0.0003$ \\
Streptococcus pneumoniae & $1(3 \%)$ & $5(15 \%)$ & 0.02 \\
Haemophilus influenzae & $1(3 \%)$ & $1(3 \%)$ & 0 \\
Pseudomonas aeruginosa & $2(6 \%)$ & 1 & 1 \\
Escherichia coli & 0 & 1 & 1 \\
Staphylococcus aureus & 0 & 1 & 0 \\
Coxiella burnetii & 0 & 0 & \\
Streptococcus pyogenes & $2(6 \%)$ & $1(3 \%)$ & \\
Streptococcus agalactiae & 1 & \\
Cryptococcus species & & & \\
\hline
\end{tabular}

Some patients had more than one organism involved. HIV Human immunodeficiency virus

\section{RESULTS}

Forty-one HIV-infected patients with an admission diagnosis of pneumonia were identified and 36 (88\%) charts were available for review. Thirty-three non-HIV-infected patient charts were available for review.

Thirty-two of the 36 HIV-infected patients (89\%) had CAP. Two of the remaining four patients had upper respiratory tract infections, one had Kaposi's sarcoma of the lung and one had septic pulmonary emboli secondary to right-sided endocarditis. Only data from the 32 patients with pneumonia were used in subsequent analysis. Chest radiographs were reviewed on all HIV- and non-HIV-infected patients included in the study.

The two populations were similar in age, sex and race. The mean age of the HIV-infected patients was 37 years (range 29 to 57 years) and 41 years for the non-HIV-infected patients (24 to 61 years). Three HIV-infected females and four nonHIV-infected females were studied; the remainder were males. Ninety-four per cent of the subjects in both groups were Caucasian. The tobacco smoking history did not differ (58\% versus $75 \%$, not significant). The HIV-infected patients were more likely to have a past history of pneumonia (50\% versus $20.8 \%, \mathrm{P}<0.005)$. Twelve HIV-infected patients had prior PCP. The risk factors for HIV infection were as follows: $60 \%$ homosexual, $11 \%$ heterosexual, $11 \%$ intravenous drug use, $5 \%$ transfusion-related and 20\% unknown. The mean ( \pm SD) T helper cell count was $70.9 \pm 98.5$ cells $/ \mathrm{mm} 3$. In the HIV patient population, 53\% (17 of 32 ) had a prior AIDSdefining illness. For six patients, this event was their AIDS- defining illness. Only one patient was unaware of his HIV status on admission.

No significant differences were found in the presenting symptoms of pneumonia, including dyspnea, cough, sputum production, hemoptysis and pleuritic chest pain, in these two groups of patients. Mean vital signs on admission were similar for both groups, including pulse rate (HIV $105 \pm 20$ beats/min versus non-HIV $102 \pm 24$, not significant), respiratory rate (HIV $26 \pm 8 /$ min versus non-HIV $23 \pm 7$, not significant) and temperature (HIV $38.3 \pm 1.4^{\circ} \mathrm{C}$ versus non-HIV $\left.37.5 \pm 2.1^{\circ} \mathrm{C}\right)$. The chest radiographs of the non-HIV-infected patients demonstrated an alveolar pattern more frequently (79\% versus $34 \%, \mathrm{P}<0.01$ ), while the $\mathrm{HIV}$-infected patients had interstitial disease more commonly $(60 \%$ versus $21 \%$, $\mathrm{P}<0.01$ ). Only two HIV-infected patients had a mixed alveolar interstitial pattern (Table 1).

An etiological diagnosis of pneumonia was made more frequently in the HIV patients (66\% versus $27 \%, \mathrm{P}<0.005$ ). P carinii was the most common cause of pneumonia (definite in 10, possible in six) in the HIV group while Streptococcus pneumoniae was more common in the non-HIV group. Sixteen of the $21(76 \%)$ HIV-infected patients with pneumonia of known etiology had PCP while only one had S pneumoniae. Two HIVinfected patients had mixed bacterial and PCP infections. Two HIV-infected patients had Pseudomonas aeruginosa pneumonia. The non-HIV-infected patients had S pneumoniae as the cause of $55 \%$ of the cases with pneumonia of known etiology (Table 2). 
All laboratory results were comparable between the two groups except that the white blood cell count on admission was higher for the non-HIV group $\left(12.7 \pm 5.6 \times 10^{9} / \mathrm{L}\right.$ versus $5.7 \pm 3.1 \times 10^{9} / \mathrm{L}, \mathrm{P}=0.003$ ). Serum chemistry was analyzed more frequently during the course of one admission for the HIV patients ( 7.3 versus 4.3 per admission). The mean number of complete blood cell counts and mean number of chest radiographs did not differ between the two groups. HIV-infected patients with pneumonia were more likely to have blood cultures done ( $94 \%$ versus $70 \%, \mathrm{P}=0.03)$ and to have undergone bronchoscopy $(27 \%$ versus $0 \%, \mathrm{P}<0.001)$.

The length of stay in hospital was similar for both groups (HIV-infected patients $13.0 \pm 12.0$ days versus non-HIV infected patients $8.6 \pm 5.11$, not significant). There were no differences in intensive care unit admissions (two HIV-infected patients versus three non-HIV-infected patients) or need for mechanical ventilation (three HIV-infected patients versus two non-HIV-infected patients) between the two groups. In the HIV-infected cohort eight of $16(50 \%)$ received steroids for their PCP. Short term and long term survival were significantly reduced in the HIV-infected population with CAP. The HIV-infected patients had a $25 \%$ (eight of 32) in-hospital mortality while none of the non-HIV infected patients died in hospital $(P=0.002)$. Two of the HIV-infected patients requiring mechanical ventilation died during their admission; one required admission to the intensive care unit while the other remained in a stepdown unit. Both patients' deaths were directly attributable to the pneumonic process. Survival at one year after the onset of pneumonia was 30\% in the HIV-infected patients and $94 \%$ in the non-HIV-infected patients.

of the eight HIV-infected patients who died while in hospital, three had a diagnosis of CAP of unknown etiology. The T helper cell count for this group ranged from 2 to 210 cells $/ \mathrm{mm}^{3}$ (median 10 cells $/ \mathrm{mm}^{3}$ ). Six of these patients had a prior diagnosis of AIDS and all had been diagnosed with HIV for longer than one year (range 1.3 to eight years). The length of stay from admission to death ranged from one to 27 days in hospital (median three days).

No difference was found in the use of antiretroviral drugs or PCP prophylaxis between the 16 HIV-infected patients with a diagnosis of PCP and the 16 without PCP (69\% versus $56 \%$ for antiretrovirals, not significant, and $62 \%$ in both groups for PCP prophylaxis, not significant). Of those with PCP, four were receiving zidovudine and seven didanosine at admission. of the HIV-positive patients without PCP, four patients were on zidovudine, four were receiving didanosine and one was receiving combination therapy (zidovudine and didanosine). The use of PCP prophylaxis was equivalent in both groups: among those with PCP, two were receiving trimethoprim/sulfamethoxazole (TMP/SMX), three dapsone, two atovaquone and four aerosolized pentamidine (AP). Of the HIV-infected group without PCP, two patients were receiving TMP/SMX, five dapsone and three AP. Five of the HIV-infected patients were receiving other antimicrobial agents before admission. Three of these patients eventually had a diagnosis of PCP while two had bacterial pneumonia.

\section{DISCUSSION}

Since the early 1980s, many investigators have examined pulmonary complications in the HIV-infected population $(1,9)$. Special attention has been focused on infectious pulmonary diseases in this patient group, including PCP, tuberculosis and bacterial pneumonia. In December 1992, the CDC expanded their definition of AIDS to include recurrent bacterial pneumonia as an AIDS-defining illness (4). This was promptly added to the Canadian definition (5).

An etiological diagnosis of pneumonia is key to appropriate treatment. Multiple prospective studies have examined the etiologies of CAP and found that $43 \%$ to $56 \%$ of pneumonias were of unknown etiology $(6,10-13)$. In our retrospective study, $73 \%$ of the non-HIV-infected and $34 \%$ of the HIV-infected patients had no etiological diagnosis for their pneumonia.

Bacterial pulmonary infections appear to occur at an increasing frequency in HIV-infected individuals. The incidence varies from $3 \%$ to $31 \%$ in hospitalized patients, the higher incidence involving intravenous drug users $(1,14)$. Pneumococcus and Haemophilus influenzae are the most common bacterial causes of CAP in HIV-infected patients $(15,16)$. Other common bacterial pathogens that cause pneumonia in this group include Staphylococcus aureus, Klebsiella pneumoniae, Rhodococcus equi, Moraxella catarrhalis and Legionella pneumophila $(1,17,18)$. The incidence of pneumococcal pneumonia among HIV-infected persons has been reported to be up to 17.5 times the rate in the general population (19). In our patients infected with HIV, only one was found to have S pneumoniae infection. Although our total number of HIV-infected patients studied was small, it appears that pneumococcus is not as common a bacterial pathogen at our centre as in other geographical areas. It has been recommended that the 23valent pneumococcal vaccine be administered to persons with HIV to prevent invasive pneumococcal disease (20). The efficacy of the pneumococcal vaccine is unknown (19). All HIVinfected persons seen at our centre are offered pneumococcal vaccine at their first visit. Whether vaccination resulted in the low rate of pneumococcal disease in our HIV-infected population is speculative.

Our data indicate that PCP remains the most common etiology of CAP in HIV-infected patients requiring hospital care for this illness. In the United States and in the United Kingdom, PCP remains an important illness in the HIV-infected patient $(2,21)$. In France and Edinburgh, however, the number of patients with PCP appears to be decreasing $(3,22)$. Caiaffa et al (14) found that a low T helper cell count, low socioeconomic status and intravenous drug use were the most significant risk factors for bacterial CAP in HIV-infected patients. In a large population of HIV-infected intravenous drug users, bacterial pneumonia was the most common cause of CAP (3). This was not the case in a population consisting mostly of homosexual males, in which PCP was the most common etiological diagnosis (21). Similarly, our population consists mostly of homosexual males with only $11 \%$ intravenous drug users. It is noteworthy that both patients with $\mathrm{P}$ aeruginosa pneumonia were intravenous drug users. 
From 1982 to $1990,4 \%$ (54 of 1350 ) of patients with CAP admitted to our institution were HIV-positive, and 61\% (33 of 54 ) of these had a diagnosis of PCP. This compares with the current rate of $50 \%$ (16 of 32) for PCP among our HIV patients with pneumonia. A question that remains is whether the rate of PCP is decreasing as a result of increasing antiretroviral drug use and PCP prophylaxis. The rate of PCP in our hospitalized HIV-infected patients, despite prophylaxis, remains high. Our study may be biased by including only hospitalized patients with CAP and by our inability to assess compliance with PCP prophylaxis. Current regimens have failure rates of $4 \%$ to $18 \%$ and up to $9 \%$ for secondary and primary prophylaxis, respectively (23). Failure rates for PCP prophylaxis are higher when $\mathrm{T}$ helper cell count falls below 75 to 100 cells/mm3 and are more frequently encountered with AP use than with TMP/SMX or dapsone/TMP (24).

Clinical manifestations of pneumonia did not differ in our two populations. This comparison is limited by the nature of a retrospective study and information available in charts. The review of chest radiographs did show a difference between the two groups. The predominance of interstitial patterns in the HIV-infected patients can be explained by the etiology profiles with a large majority having a diagnosis of PCP.

The use of laboratory tests was essentially the same in both groups. HIV-infected patients had more chemistry tests done, which may be explained by our pentamidine protocol, which requires regular verification of blood glucose and renal function. Our HIV-infected population underwent a more intensive diagnostic work-up than the non-HIV infected group, including blood cultures and bronchoscopy. This is not surprising because empirical therapy has been advocated in the non-HIV-infected patient with CAP. Initial antimicrobial management guidelines for CAP have been established by the Canadian Community-Acquired Pneumonia Consensus Group (25). No such guidelines exist for the HIV-infected patient with CAP, nor should there be such guidelines. The range of diagnoses in this population is vast, with the potential need for toxic and prolonged courses of therapy and possible lifelong prophylaxis. An etiological diagnosis should therefore be sought whenever possible (26).

As expected in our population with moderately advanced disease, the HIV-infected group had a high in-hospital and postdischarge mortality. Studies predicting death from CAP have identified factors that allow stratification of patients into various levels of risk for poor outcome. Farr et al (27) concluded that tachypnea, diastolic hypotension and elevated blood urea nitrogen were independently associated with death from pneumonia. These factors have not been studied in HIV-infected patients with CAP. No significant differences were found in these parameters in our two patient groups, although a marked difference in survival was noted between the two groups.

A decrease in mortality from PCP in HIV-infected patients has been observed with the introduction of prophylaxis (see above), glucocorticoids as adjuvant therapy $(23,28,29)$ and more aggressive supportive treatment (26,30-32). Survival rates for a first episode of PCP with early diagnosis and initiation of treatment are approximately $90 \%$. These can fall pre- cipitously to $10 \%$ if there is a lack of response to therapy necessitating a change in treatment regimen (26). Although a low Thelper cell count (less than 200 cells $/ \mathrm{mm}^{3}$ ) is an excellent predictor of the risk of developing PCP, hypoxemia appears to be the best prognostic factor of mortality in HIV-infected patients with PCP $(28,33)$. The consensus statement on the use of corticosteroid therapy for PCP issued in 1990 reviewed five randomized trials evaluating the use of corticosteroids as adjuvant therapy. It was found that when given early in the course of treatment ( 24 to $72 \mathrm{~h}$ ), in patients with moderate to severe disease, corticosteroids could decrease failure of oxygenation, need for mechanical ventilation and death by approximately $50 \%(28)$.

It has been more difficult to show that supportive therapy such as mechanical ventilation in the face of respiratory failure favourably affects survival in this population. Five per cent to $30 \%$ of first PCP episodes will lead to death from acute respiratory failure (ARF) (30). Survival of PCP with mechanical ventilation as a treatment for ARF was felt to be less than 15\% (31). With improvement of supportive care, in-hospital survival of HIV-infected patients requiring mechanical ventilation for PCP and $\mathrm{ARF}$ is $25 \%$ to $50 \%$. Long term survival rates one year postdischarge in patients with PCP and ARF requiring mechanical ventilation are as high as $80 \%$ (31). Unfortunately, there are no good prognostic indicators to predict who will develop ARF or require mechanical ventilation. Brooks et al (26) found high mortality rates in patients with multiple admissions, multiple pulmonary infections, leukocytosis, elevated serum lactate dehydrogenase, decreased $\mathrm{PaO} 2$, decreased $\mathrm{CO} 2$ tension and diminished serum albumin levels. The decision to admit to an intensive care unit and to use mechanical ventilation in patients with PCP, AIDS and ARF remains a complex one, which must involve the patient, the physician and up-to-date knowledge of data concerning the issue.

In-hospital mortality in our group of $32 \mathrm{HIV}$-infected patients was 25\%, while from 1982 to 1990 the in-hospital mortality rate for HIV-infected patients with CAP was $17 \%$ (nine of 54, not significant). Although this difference in mortality is not significant, it may suggest that the patients admitted to hospital in the 1990 s have more advanced disease.

\section{CONCLUSIONS}

CAP is an important cause of morbidity and mortality in HIV-infected patients. This study shows that there is a need for a prospective study comparing the HIV-infected population with the non-HIV-infected population with CAP to assess further the etiological differences, prognostic indicators for morbidity and mortality in HIV patients, and evaluate approaches to therapy if an etiology cannot be defined.

ACKNOWLEDGEMENTS: The chart review was approved by the vicepresident of medical affairs at our institution.

\section{REFERENCES}

1. Murray JF, Mills J. Pulmonary infectious complications of human immunodeficiency virus infection. Am Rev Respir Dis 1990;141:1356-72,1582-98. 
2. Hoover DR, Saah AJ, Bacellar H, et al. Clinical manifestations of AIDS in the era of pneumocystis prophylaxis. N Engl J Med 1993;329:1922-6.

3. Magnenat JL, Nicod LP, Auckenthaler R, et al. Mode of presentation and diagnosis of bacterial pneumonia in human immunodeficiency virus-infected patients. Am Rev Respir Dis 1991;144:917-22.

4. Centers for Disease Control. 1993 revised classification system for HIV infection and expanded surveillance case definition for AIDS among adolescents and adults. MMWR 1992;41(RR-17):1-19.

5. Revision of the surveillance case definition for AIDS in Canada. Can Commun Dis Rep 1993;19:116-7.

6. Murray PR, Washington JA. Microscopic and bacteriologic analysis of expectorated sputum. Mayo Clin Proc 1975;50:339-44.

7. Fang GD, Fine M, Orloff J, et al. New and emerging etiologies for community-acquired pneumonia with implication for therapy. Medicine 1990;69:307-16.

8. Dawson-Saunders B, Trapp RG. Basic and Clinical Biostatistics. Norwalk: Appleton and Lange, 1994:102-3,143-61.

9. Meduri GU, Stein DS. Pulmonary manifestations of acquired immunodeficiency syndrome. Clin Infect Dis 1992;14:98-113.

10. MacFarlane JT, Colville A, Guion A, et al. Prospective study of aetiology and outcome of adult lower-respiratory-tract infections in the community. Lancet 1993;341:511-4.

11. Woodhead MA, MacFarlane JT, McCracken JS, et al. Prospective study of the aetiology and outcome of pneumonia in the community. Lancet 1987;i:671-4.

12. Marrie TJ, Durant H, Yates L. Community-acquired pneumonia requiring hospitalization: 5-year prospective study. Rev Infect Dis 1989;11:586-99.

13. Bates JH, Campbell GD, Barren AL, et al. Microbial etiology of acute pneumonia in hospitalized patients. Chest 1992;101:1005-112.

14. Caiaffa WT, Graham NMH, Vlahov D. Bacterial pneumonia in adult populations with human immunodeficiency virus (HIV) infection. Am J Epidemiol 1993;138:909-22.

15. Hirschtick R, Glassroth J. Bacterial, fungal and viral pneumonia in HIV-infected patients. Semin Respir Crit Care Med 1995;16:207-15.

16. Burack JH, Hahn JA, Saint-Maurice D, et al. Microbiology of community-acquired bacterial pneumonia in persons with and at risk for human immunodeficiency virus type 1 infection. Implications for rational empiric antibiotic therapy. Arch Intern Med 1994;154:2589-96.

17. Polsky B, Gold JWM, Whimbey E, et al. Bacterial pneumonia in patients with AIDS. Ann Intern Med 1986;104:38-41.

18. Witt DJ, Craven DE, McCabe WR. Bacterial infections in adult patients with acquired immunodeficiency sydrome (AIDS) and AIDS-related complex. Am J Med 1987;82:900-6.

19. Jannoff EN, Breiman RF, Daley CL, et al. Pneumococcal disease during HIV infection. Epidemiologic, clinical and immunologic perspective. Ann Intern Med 1992;117:314-24.

20. Center for Disease Control. Recommendations of the Advisory Committee on Immunization Practices (ACIP): use of vaccines and immune globulins in persons with altered immunocompetence. MMWR 1993;42(RR-4):1-15.

21. Pitkin AD, Grant AD, Foley NM, et al. Changing patterns of respiratory disease in HIV positive patients in a referral centre in the United Kingdom between 1986-7 and 1990-1. Thorax 1993;48:204-7.

22. Willcox L, Cowan F, Brettle RP, et al. The spectrum of chest infections in HIV positive patients in Edinburgh. J Infect 1992;24:37-42.

23. Masur H. Prevention and treatment of pneumocystis pneumonia. N Engl J Med 1992;327:1853-60.

24. Saah AJ, Hoover DR, Pang Y, et al. Predictors for failure of Pneumocystis carinii pneumonia prophylaxis. JAMA 1995;273:1197-202.

25. Mandell LA, Niederman M, The Canadian Community-Acquired Pneumonia Consensus Conference Group. Antimicrobial treatment of community-acquired pneumonia in adults: A conference report. Can J Infect Dis 1993;4:25-8.

26. Brooks KR, Ong R, Spector RS, et al. Acute respiratory failure due to Pneumocystis carinii pneumonia. Crit Care Clin 1993;9:31-48.

27. Farr BM, Sloman AJ, Fisch MJ. Predicting death in patients hospitalized for community-acquired pneumonia. Ann Intern Med 1991;115:428-36.

28. The National Institutes of Health-University of California Expert Panel for Corticosteroids as Adjunctive Therapy for Pneumocystis Pneumonia. Consensus statement on the use of corticosteroids as adjunctive therapy for pneumocystis pneumonia in the acquired immunodeficiency syndrome. N Engl J Med 1990;323:1500-4.

29. Sattler FR, Feinberg J. New developments in the treatment of Pneumocystis carinii pneumonia. Chest 1992;101:451-7.

30. Staikowsky F, Lafon B, Guidet B, et al. Mechanical ventilation for Pneumocystis carinii pneumonia in patients with the acquired immunodeficiency syndrome. Is the prognosis really improved? Chest 1993;104:756-62.

31. Franklin C, Friedman Y, Wong T, et al. Improving long-term prognosis for survivors of mechanical ventilation in patients with AIDS with PCP and acute respiratory failure. Arch Intern Med 1995;155:91-5

32. Nielsen TL, Guldager H, Pedersen C, et al. The outcome of mechanical ventilation in patients with an AIDS-associated primary episode of Pneumocystis carinii pneumonia. Scand J Infect Dis 1991;23:37-41.

33. Kovacs JA, Masur J. Prophylaxis for Pneumocystis carinii pneumonia in patients infected with human immunodeficiency virus. Clin Infect Dis 1992;14:1005-9. 


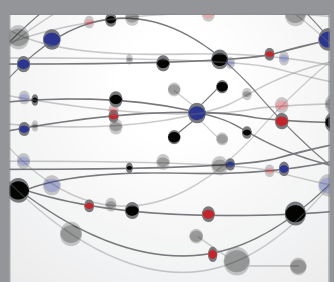

The Scientific World Journal
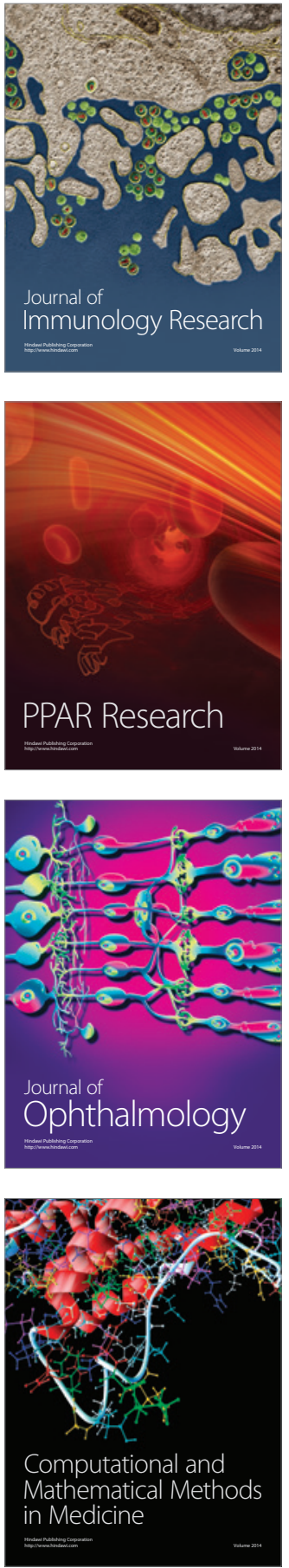

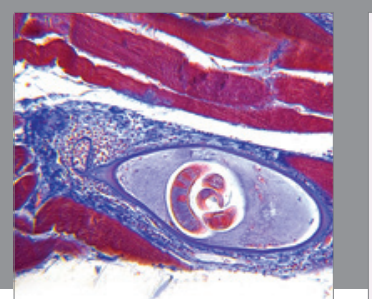

Gastroenterology Research and Practice

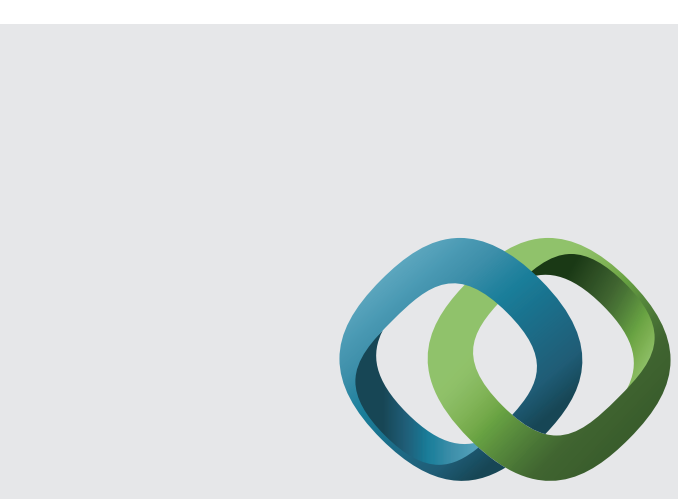

\section{Hindawi}

Submit your manuscripts at

http://www.hindawi.com
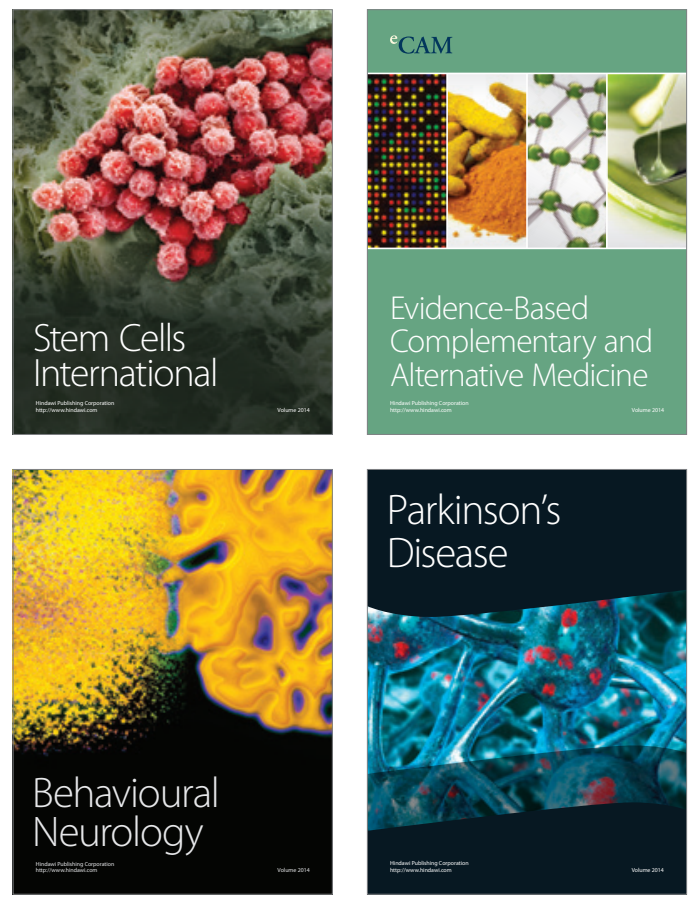
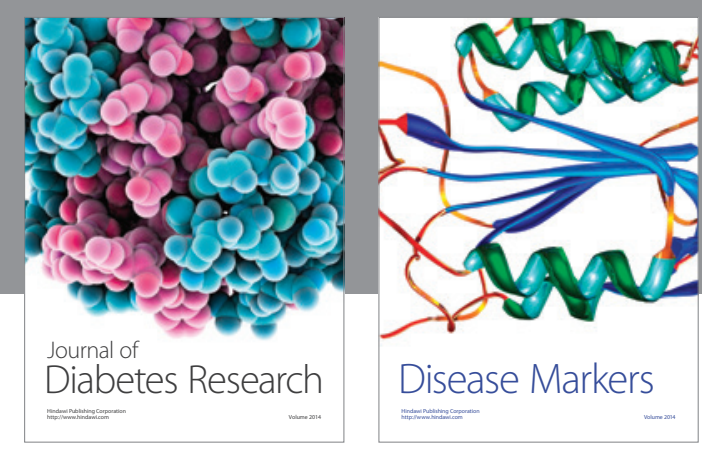

Disease Markers
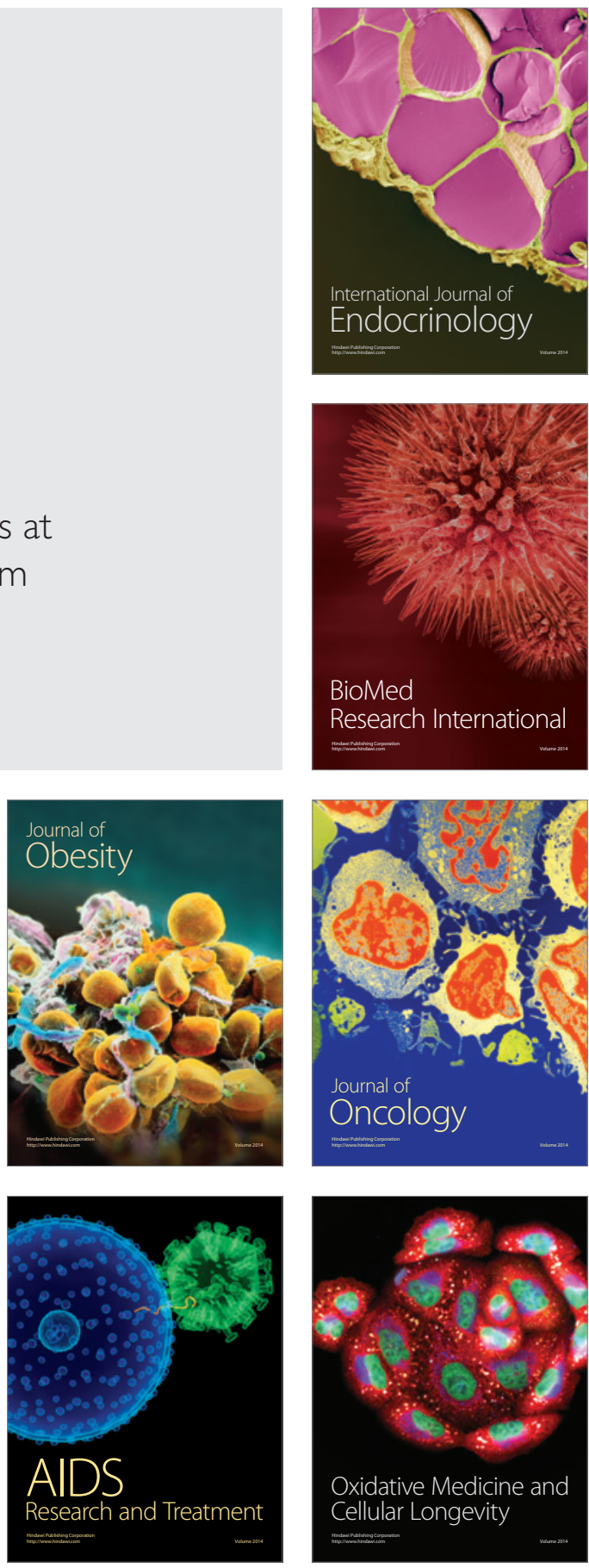